\title{
A New Sensor Rapid Analysis of Silicon in Hot Metal Electromotive Force Method ${ }^{*}$
}

\author{
By Masao MATSUOKA,** Kuniyoshi URATA,** Ryuji FUJIWARA,** \\ Mitsuharu TOMINAGA ${ }^{* *}$ and Toshihiro OGURA ${ }^{* *}$
}

\begin{abstract}
Synopsis
$A$ probe for accurate and rapid determination of $\mathrm{Si}$ contents in hot metal has been developed by thermal electromotive force (EMF) measurement. The sensor has a pair of electrodes for measuring thermal EMF, which are housed in a large steel chamber to cool hot metal sample. Measurements are completed in about 1 min after immersion of a few seconds.

Laboratory study has been made on the applicability of the sensor to blast furnace hot metal. The adverse effects of hot metal temperature on measurement have been eliminated. It has been confirmed that there is little effect of $\mathrm{G}$ and $\mathrm{Mn}$ on measurement.
\end{abstract}

Key words: silicon sensor; silicon analysis; thermal electromotive force measurement; hot metal pretreatment; desiliconization; dynamic control.

\section{Introduction}

In recent years, desiliconization of hot metal has been carried out extensively in iron and steel making processes. Removal of $\mathrm{Si}$ from hot metal can be achieved by the addition of mill scale. The controlling procedure in such desiliconization process requires the information of $\mathrm{Si}$ content in hot metal. The concentration of $\mathrm{Si}$ in hot metal, however, varies significantly even during tapping. The key to better control of the Si levels in hot metal is, therefore, the availability of a sensor which allows rapid determination of the Si content.

Until now, chemical analysis, spectrographic analysis, etc. have been used. Rapid analysis for Si determination has been tried, ${ }^{1-3)}$ but further improvements remain in terms of handling, performance and production cost.

In a foundry, Si content of hot metal has been determined from thermal electromotive force (EMF) measurement of samples. This is called "Thermal EMF Method" based on the principle that EMF values are a function of $\mathrm{Si}$ content. ${ }^{4-7)}$ This technique used for cast iron involves sampling of hot metal and subsequent mechanical polishing before measurement: it will require approximately $7 \mathrm{~min}$ to complete an analysis. From an engineering point of view, a $\mathrm{Si}$ sensor has been developed for this thermal EMF method to ensure rapid measurements together with higher accuracy and cost reduction.

During the development work, bearing in mind the application to blast furnace hot metal, we examined the thermal EMF characteristics of Sicontaining pig iron, the possibility to eliminate the adverse effect of hot metal temperature on thermal $\mathrm{EMF}$ measurements and effects of $\mathrm{G}$ and $\mathrm{Mn}$ on $\mathrm{Si}$ measurements in hot metal by using Si sensor. In laboratory, the new $\mathrm{Si}$ sensor was proved high accuracy and rapid measurements which were completed about $1 \mathrm{~min}$.

\section{Principle}

\section{Conventional Thermal EMF Method}

For a thermocouple with a joint of metal A and binary alloy $\mathrm{AB}$, the thermal EMF at the junction depends on the content of $\mathrm{B}$ when the temperature at hot junction is fixed. If the thermocouple elements are pure iron and pig iron with $\mathrm{Si}$, the $\mathrm{Si}$ concentration in a sample can be determined.4)

In casting foundry, this principle has been put to practical use for the determination of $\mathrm{Si}$ content ${ }^{6)}$ in the following procedure:

1) Casting of molten iron in a mold.

2) Removal of a sample from the mold and waterquenching or air-cooling to room temperature.

3) Polishing of the sample surface for eliminating the adverse effects on thermal EMF such as the contact resistance between sample and electrodes created by oxidation and chilled layer on the surface.

4) Two electrodes are contacted with the polished surface of the sample.

5) By heating one electrode to make a temperature gradient against the other, thermal EMF between those electrodes is measured to determine the $\mathrm{Si}$ content.

\section{Thermal EMF Method by Using a Si Sensor}

A disposable immersion sensor has been developed by using the same thermal EMF method for Si measurement for the purpose of rapid and efficient measurements and cost saving. Figure 1 compares the conventional method as used in a foundry with the present sensor method. In the sensor method, hot metal is sampled as in the conventional method, but the difference between the sensor method and the conventional method is the measuring method after sampling, that is, a temperature difference is created between two electrodes in the solidification and cooling process of the sample for thermal EMF to calculate the $\mathrm{Si}$ contents. This reduces the time for measurements to about 1 from $7 \mathrm{~min}$ of the conventional method.

* Based on the paper presented to the 112th ISIJ Meeting, October 1986, S877, at Nagoya University in Nagoya. Manuscript received on April 3, 1987; accepted in the final form on July 3, 1987. (C) 1987 ISIJ

** Research Laboratories, Yamari-Electronite Co., Ltd., Minamibefu-cho, Settsu, Osaka Pref. 566. 


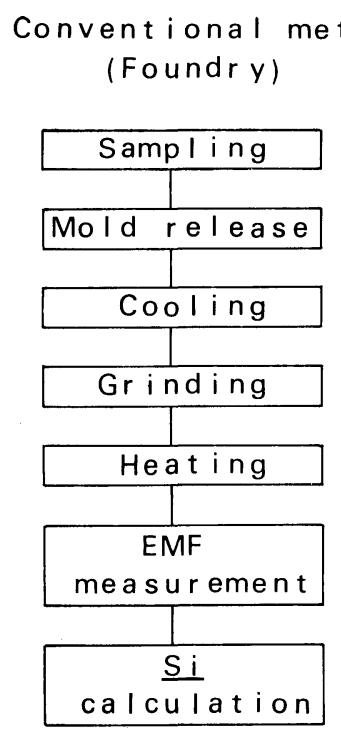

Probe method

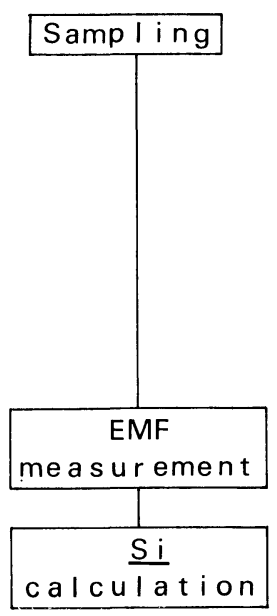

Fig. 1. Comparison of the conventional method with the present sensor method.

\section{Sensor Structure}

Figure 2 shows the schematic diagram of the detector of Si sensor, and Fig. 3 shows the measurement system. The electrodes are protected from oxidation to assure high accuracy by the sample obtained when hot metal enters into the sensor. The simple structure of this sensor will save manufacturing cost.

The sensor consists of a large chamber made of steel as cooling medium. Inside the chamber is located two sets of chromel-alumel thermocouples. Each thermocouple is covered by an insulator to expose only the tip for the hot junction as an electrode in contact with the sample. The plus element (chromel) of each thermocouple is used as a leadwire for thermal EMF measurement. As shown in Fig. 3, measured $\Delta E$ corresponds to a temperature difference, $\Delta T$, between the two hot junctions, $T 1$ and $T 2$.

\section{Experiments}

The thermal EMF measurements with the Si sensors were conducted with $\mathrm{Fe}-\mathrm{C}-\mathrm{Si}-\mathrm{Mn}$ alloys, which were melted in a high frequency induction furnace. A magnesia crucible was charged initially with electrolytic iron and heated in an ambient atmosphere. The molten iron was subsequently saturated with $\mathrm{G}$ by the addition of granules of high purity graphite. Silicon and Mn contents were adjusted by adding ferro-Si and metallic $\mathrm{Mn}$, respectively, to the molten iron. All the experiments were conducted at the temperature range between 1250 and $1510^{\circ} \mathrm{C}$.

\section{Measuring Procedure of Thermal EMF Method}

Specimen was obtained by sucking hot metal into a quartz tube and was quenched in water as a bar of $3.5 \mathrm{~mm}$ diameter and of above $100 \mathrm{~mm}$ length. Two sets of chromel-alumel thermocouples were welded on both ends of the specimen. Thermal EMF generated between two plus thermocouple (chromel) wires was

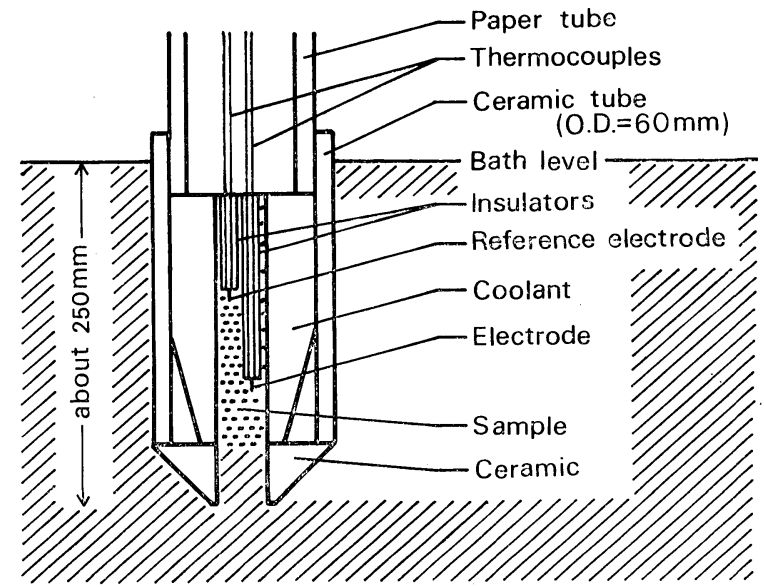

Fig. 2. Schematic diagram of Si sensor.

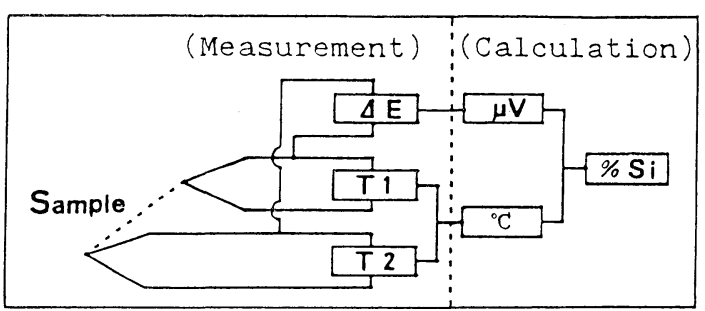

Fig. 3. Measurement system of Si sensor.

measured in a platinum resistance furnace (horizontal type) by creating a temperature difference between both ends of the specimen.

\section{Experimental Procedure with the Present Sensor}

(1) The sensor was manually immersed into the bath with the top about $250 \mathrm{~mm}$ below the molten iron surface. Upon immersion the molten iron flowed into the cooling chamber and solidified to generate a temperature gradient along the vertical direction within solidified iron. Such a thermal gradient can be directly detected by means of the chromel-alumel thermocouples (see Fig. 2).

(2) After immersion of a few sec, the sensor was removed from the bath and cooled in air. When the reference electrode temperature (the lower temperature) $T 1$ dropped to a predetermined temperature, the temperature difference $\Delta T$ between $T 1$ and $T 2$ and the thermal EMF, $\Delta E$, were measured for Si content determination. Figure 4 shows the changes in EMF and temperature with time after immersion.

(3) The calculated $\mathrm{Si}$ contents were compared with the real values obtained by chemical analysis of the samples.

\section{Result and Discussion}

\section{Characteristics of EMF for Si-containing Pig Iron}

Since the thermal EMF method has been used at foundries, the EMF characteristics have been studied only for cast iron containing $2 \sim 3 \% \mathrm{C}$ with a relatively high range of $\mathrm{Si}$ content. The present study is focused on blast furnace hot metal and the EMF characteristics of white pig iron containing about 


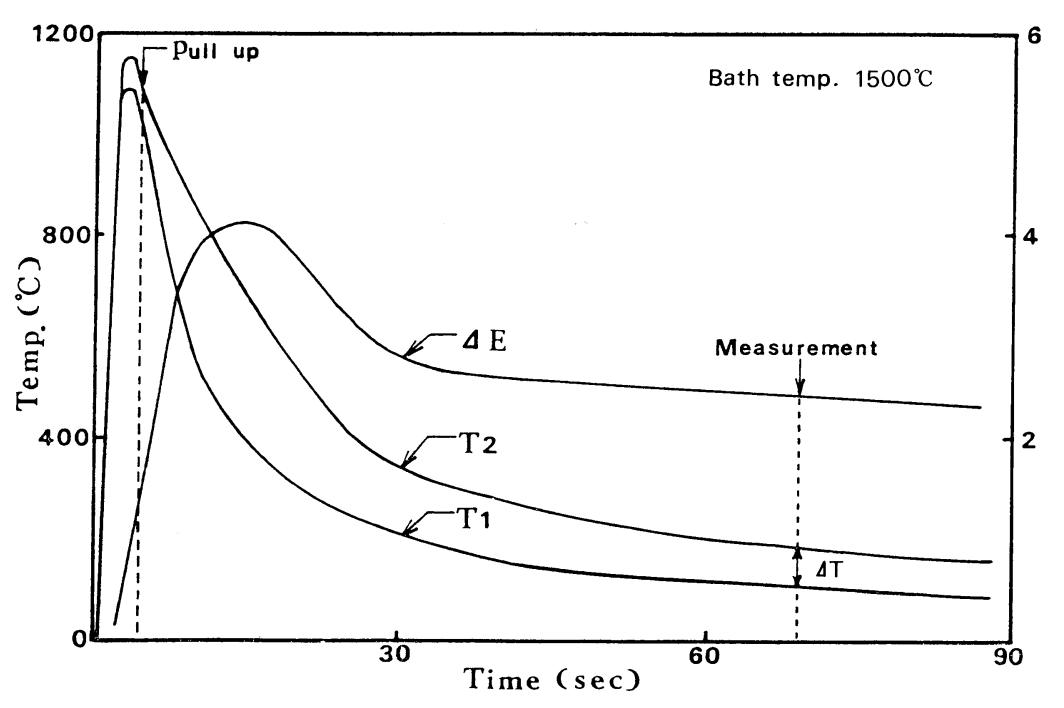

Fig. 4. Changes in EMF and temperature after immersion.

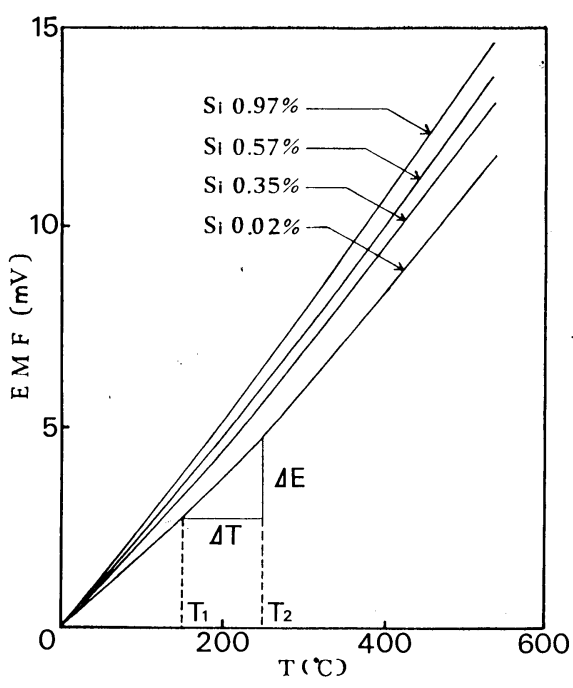

Fig. 5. Effect of Si content on EMF between sample and chromel.
$4 \% \mathrm{C}$ and $1 \%$ or less Si. White pig iron is used because the other types such as gray pig iron have a wide range of ferrite fraction according to the cooling speed, which in turn influences thermal EMF even if the compositions are identical. ${ }^{5,7)}$

Figure 5 shows the effect of $\mathrm{Si}$ content on the thermal EMF generated at the joint of pig iron and chromel. The thermal EMF values depend on $\mathrm{Si}$ contents in this range of $\mathrm{C}$ and $\mathrm{Si}$. Figure 6 shows the effect of $T 1$ on the thermal EMF generated between pig iron and chromel when the temperature difference $\Delta T$ between $T 1$ and $T 2$ is $100^{\circ} \mathrm{G}$. When $T 1$ is below $200^{\circ} \mathrm{G}, \Delta E$ shows high dependence on the $\mathrm{Si}$ content and the fluctuations of measured values are so small as to ensure accurate measurements. The sensor was, therefore, designed so that $T 1$ drops rapidly below $200^{\circ} \mathrm{C}$ and $\Delta T$ is kept about $100^{\circ} \mathrm{G}$.

\section{Elimination of the Effects of Hot Metal Temperature}

Solidification structure in pig iron sample affects the thermal EMF. Thus it is very important to design the Si sensor so as to get an identical solidification structure in the sample at any hot metal temperature.

To study the most suitable cooling chamber, various shapes of the chamber were tested by observing, with an optical microscope, the microstructure solidified inside the cooling chamber. The tests show that a sensor with a large steel chamber is capable of quickly solidifying the sampled hot metal to obtain an optimum microstructure independent of the variation of hot metal temperature. Figures $7(a)$ and (b) show the microstructure of samples about $5 \% \mathrm{C}$ (after measurements) obtained by a sensor having the most suitable design. The hot metal temperatures were $1390^{\circ} \mathrm{C}$ (a) and $1450^{\circ} \mathrm{C}$ (b). The both samples were white pig iron based on proeutectic cementite and ledeburite. However, in the microstructure of Fig. 7(b), graphite was partly observed. This was a result of the crystallization of hypereutectic $\mathrm{C}$. The effects of graphite on thermal EMF measurements is negligible since the present sensor provides high accuracy, as is shown in the following.

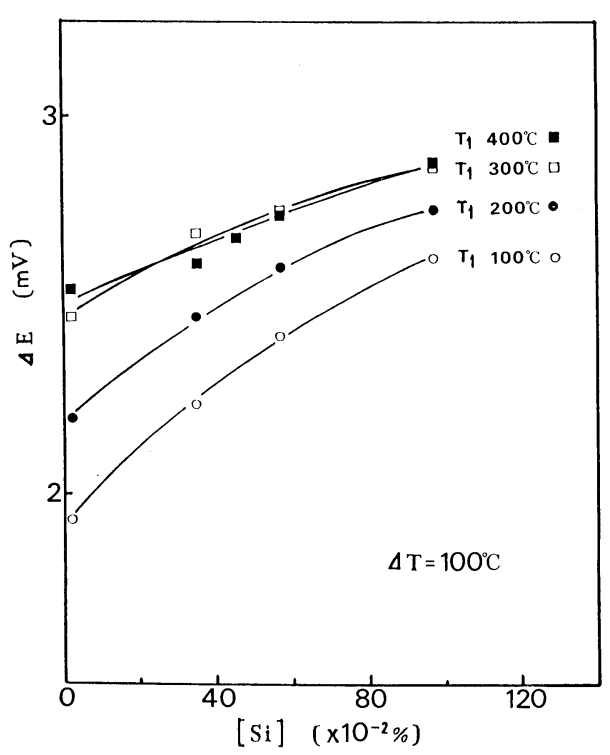

T1: Lower temperature

T: Temperature difference of $100^{\circ} \mathrm{G}$

Fig. 6. Effect of $T 1$ on thermal EMF between sample and chromel.

\section{Effect of $\mathrm{C}$ and $\mathrm{Mn}$ in Hot Metal on Measured Values}

Carbon content in hot metal is relatively high (3 $5 \%$ ) as compared with the other elements and changes greatly for every charge. In some cases, $\mathrm{Mn}$ in hot metal amounts to as much as $1 \%$. Ibaraki et al. have reported that in the thermal EMF measurement of cast iron ( $\mathrm{Fe}-\mathrm{C}-1 \% \mathrm{Si}), \mathrm{C}$ (3\% or less) influences thermal EMF values.7) Therefore, the effect of $\mathrm{C}$ and $\mathrm{Mn}$ on thermal EMF values was examined quantitatively. Figure 8 compares the Si value between analyzed and calculated by the present sensor measurement in the range of $3 \sim 5 \% \mathrm{C}$ and $\mathrm{Mn}$ less than $1.2 \%$. The difference is $0.01 \%$ for $\mathrm{Si}$, so the effect of $\mathrm{C}$ and $\mathrm{Mn}$ on measured values is very small.

\section{Effect of Carbon}

In terms of the microstructure, graphite and cementite can be taken as inclusions and therefore they have no effect on the measured EMF values. ${ }^{7)}$ It is, 
Temperature: (a) $1390^{\circ} \mathrm{C}$, (b) $1450^{\circ} \mathrm{C}$ Fig. 7.

Microstructure of hot metal sample after measurement.
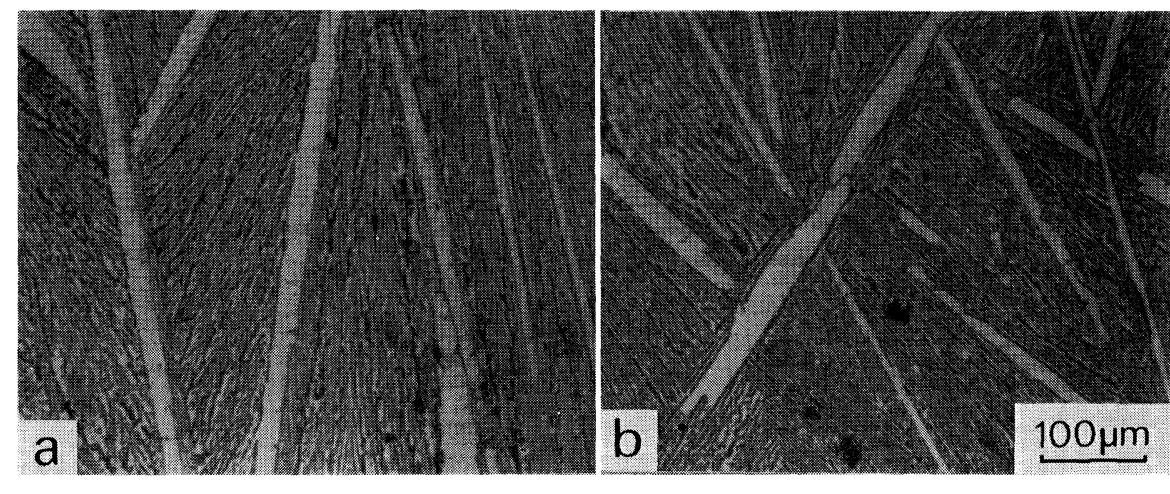
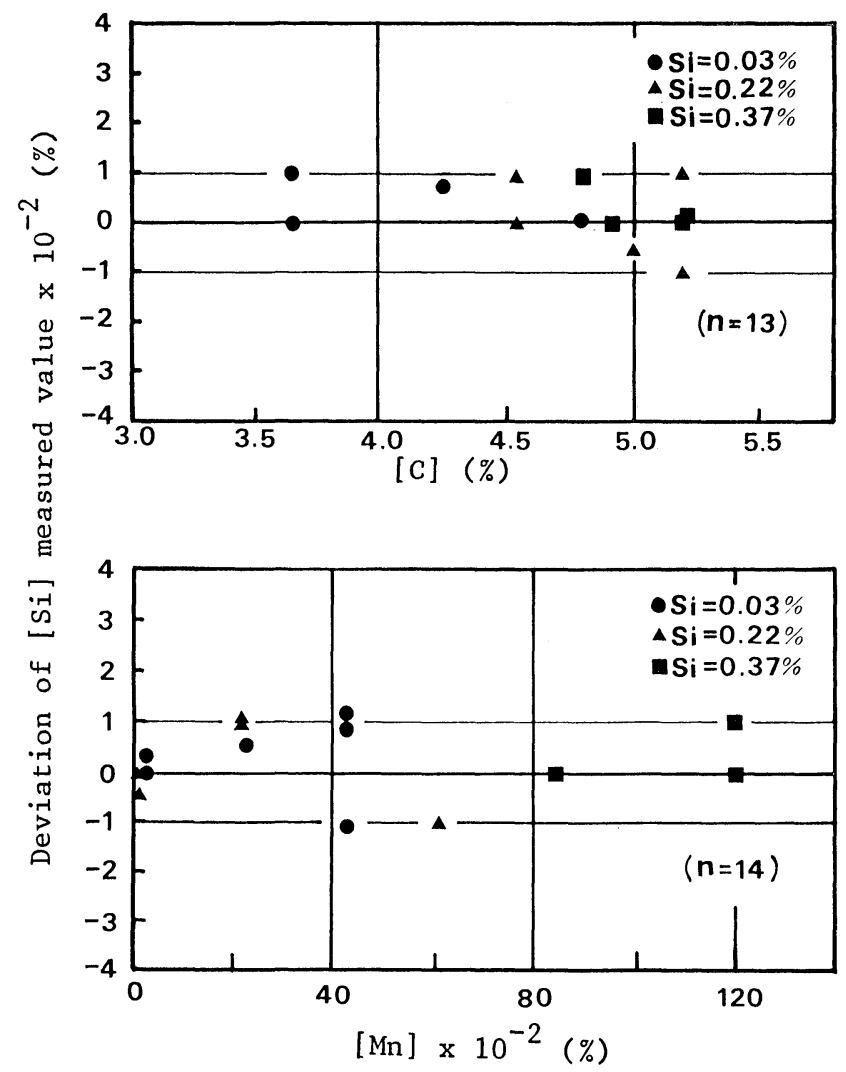

Fig. 8. Effects of $\mathrm{C}$ and $\mathrm{Mn}$ on $\mathrm{Si}$ measurement in hot metal.

however, considered that the $\mathrm{Si}$ content in ferrite changes with the variation of ferrite volume, which indirectly affects thermal EMF values. ${ }^{7)}$ In the present study, there was little effect of $\mathrm{C}$ on thermal EMF values, although the experiments done by Ibaraki et al. indicated a great effect. This difference seems to arise from the amounts of $\mathrm{C}$ and $\mathrm{Si}$ used. The present material has a small amount of Si below $1 \%$ and a large amount of $\mathrm{C}$ above $3.5 \%$. For a small amount of $\mathrm{Si}$, the dependence of thermal EMF on Si content is high and the effect of $\mathrm{C}$ content on thermal EMF is relatively low. Therefore, as long as the ferrite volume does not considerably change in accordance with a cooling speed as in gray iron, the effect of $\mathrm{C}$ is negligible. This is consistent with the report of Marukawa et al. . $^{3}$ that the white-solidification of iron taken from blast furnace hot metal improves the measuring accuracy.

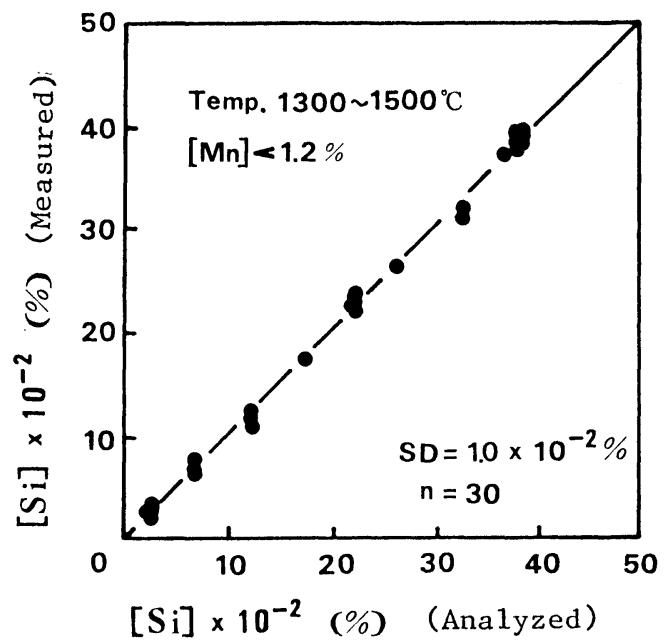

Fig. 9. Measured Si compared to analyzed values.

\section{Effect of Manganese on Measured Values}

Manganese has little effect on thermal EMF, as reported by Ibaraki et al. ${ }^{7)}$ This was considered to be due to low solubility of $\mathrm{Mn}$ in ferrite.

\section{Silicon Measurement by the Sensor}

Figure 9 shows the measuring results of laboratory molten iron of less than $1.2 \% \mathrm{Mn}$ in the temperature range of 1300 to $1500^{\circ} \mathrm{G}$. Measured Si by the present sensor shows a good correlation with the real values by chemical analysis $(n=30$, standard deviation $=0.01 \% \mathrm{Si}$ ). The present experiments prove that the effect of $\mathrm{C}$ and $\mathrm{Mn}$ is so little and the measuring accuracy is so high that the application of the sensor to hot metal pretreatment process is feasible.

\section{Conclusion}

The characteristics of the present $\mathrm{Si}$ sensor for blast furnace hot metal are summarized as follows:

(1) A sensor structure is capable of immediate thermal EMF measurement after hot metal sampling for rapid measurement of the Si content about 1 min.

(2) Since the electrodes are covered with the sample when hot metal enters into the sensor, the contact face between a sample and the electrodes is protected from oxidation which can otherwise causes EMF measurement errors.

(3) The simple structure to reduce production costs.

(4) For hot metal of $3 \sim 5 \% \mathrm{G}$ and less than 
$1 \% \mathrm{Si}$ as melt in laboratory by simulating the blast furnace pig iron, thermal EMF generated in white pig iron depends on the Si content. On the basis of the thermal EMF characteristics, a new sensor is designed which can provide $T 1$ temperature of less than $200^{\circ} \mathrm{C}$ and $\Delta \mathrm{T}$ of about $100^{\circ} \mathrm{C}$.

(5) In order to avoid the effect of solidification structure on measuring accuracy, a large steel cooling chamber was used to prepare white-solidification without regard for the hot metal temperature.

The above characteristics are included in the design of a disposable immersion type $\mathrm{Si}$ sensor, and results were obtained that $\mathrm{Si}$ measurement is independent of the effect of $\mathrm{G}$ and $\mathrm{Mn}$ with the standard deviation of $0.01 \% \mathrm{Si}(n: 30)$ for hot metal of $1300 \sim$ $1500^{\circ} \mathrm{C}$ (C: approximately $3 \sim 5 \%, \mathrm{Mn}: 1.2 \%$ and
$\mathrm{Si}: 1 \%)$.

\section{REFERENGES}

1) T. Onoe, A. Egami, S. Nishi and K. Narita: Tetsu-toHagané, 69 (1983), S879.

2) M. Iwase, H. Kitaguchi, E. Ichise, H. Nakamura, S. Moriya and S. Maruhashi: Tetsu-to-Hagané, 71 (1985), S1594 \& S1595.

3) K. Marukawa, M. Wada, M. Souma and T. Mori: Tetsuto-Hagané, 71 (1985), S1211.

4) F. Stadtler: Giesserei Techn.-Wissensch. Beihefte, (1956), No. $16,853$.

5) G. Bierwirth: Giesserei, 45 (1958), 546.

6) M. Ibaraki, K. Sugimoto, T. Morishita: Imono (J. Jpn. Foundrymen's Soc.), 31 (1959), 922.

7) M. Ibaraki, K. Sugimoto, N. Fukudome: Imono (J. Jpn. Foundrymen's Soc.), 3 (1961), 718. 